\title{
Correction of cellular immunity with biferon-C in piglets in case of specific prevention of circovirosis and mycoplasmosis
}

\author{
Aleksey Shakhov ${ }^{1}$, Sergey Shabunin ${ }^{1}$, and Mariya Zheynes ${ }^{1, *}$ \\ ${ }^{1}$ All-Russian Veterinary Research Institute of Pathology, Pharmacology and Therapy, 394087 \\ Voronezh, Russia
}

\begin{abstract}
The results of studying the effect of biferon-C containing recombinant porcine interferons -alpha and -gamma on cellular nonspecific and adaptive immunity in piglets in case of specific prevention of circovirosis and mycoplasmosis are presented. The corrective effect of the drug on cellular immunity was stated, manifested by an increase in the absorption and functional and metabolic activity of phagocytes, the relative and absolute number of T- and B-lymphocytes, T-cells with helper activity and a lower formation of the level of T-suppressors, an increase in the Thelpers/T-suppressors ratio.
\end{abstract}

\section{Introduction}

For industrial pig breeding farms, circovirus infection and mycoplasmosis are of great economic and epizootic importance [1].

The causative agent of circovirosis - circovirus type 2 (PCV-2) is common on almost all pig breeding farms [2-5], it causes the syndrome of post-weaning multisystem exhaustion, dermatitis and nephropathy syndrome, reproductive disorders, respiratory pathologies and immunodeficiency states in pigs $[6,5]$.

Specific prevention of circovirosis is the main method of infection control and prevention of concomitant secondary bacterial diseases occurring against the background of immunodeficiencies caused by PCV-2 [4, 7].

In Russia, domestic recombinant vaccine "VERRES-CIRCO" [8] and imported biological products Ingelvac CircoFLEX, Pfizer, Intervet, LLC Ceva Sante Animale [4, 9] are used.

The causative agent of mycoplasmosis, M. hyopneumoniae, is one of the main respiratory bacterial pathogens, which in combination with the porcine reproductive and respiratory syndrome virus, circovirus type 2, pasteurellae causes a complex of porcine respiratory diseases $[10,9]$.

Vaccination against mycoplasmosis is the main method of infection control and prevention [11-13]. For the prevention of the disease in many countries, RespiSure vaccine produced by Pfizer (USA) [14-16], Ingelvac MicoFlex (Boehringer Ingelheim Vetmedica,

\footnotetext{
*Corresponding author: Zheynes@mail.ru
} 
Inc., USA) [17, 18], MYPRAVAC SUIS (Laboratorios Hipra, S.A., Spain) [19], Hyoresp (Merial, France) [20] are used.

An associated vaccine against circovirosis and mycoplasmosis Ingelvac MycoFLEX ${ }^{\circledR}+$ Ingelvac CircoFLEX ${ }^{\circledR}$ (manufactured by Boehringer Ingelheim Vetmedica, Inc., USA) has been designed.

Routine immunizations of piglets against circovirosis and mycoplasmosis at the age of three weeks coincide with the development of physiological immunodeficiency associated with a decrease in the productivity of sows [21], which negatively affects the formation of specific immunity [22].

For the prevention of immunodeficiencies, increase of the general nonspecific resistance of the organism and adaptive immunity, drugs based on interferons, immunomodulators, adaptogens, stress correctors, antioxidants, probiotics, biologically active substances of a nucleic nature have been proposed [23-29].

The positive effect of biferon-C, containing a mixture of recombinant species-specific cytokines with a pronounced antiviral and antibacterial action of a wide spectrum [26], on the growth, development of piglets and the humoral immune response in case of specific prevention of circovirus infection has been detected [30].

Simultaneous administration of recombinant porcine interferons -alpha and -gamma and colibacillosis antigens to piglets increases the immune response, exhibits an anti-stress effect and relieves post-vaccination syndrome during immunization, which makes it possible to recommend them for inclusion into the composition of the complex colibacillosis antigen to increase specific immunity [31].

The aim of the research was to study the effect of biferon-C, containing recombinant porcine interferons -alpha and -gamma, on cellular immunity in piglets in case of specific prevention of circovirosis and mycoplasmosis.

\section{Materials and methods}

The studies were carried out on the industrial pig breeding farm JSC "9-ya Pyatiletka" of Liskinskiy rayon, Voronezh region in December 2019 - January 2020.

For the experiment, 2 groups of 20 clinically healthy piglets at the age of three weeks with a body weight of $\sim 6 \mathrm{~kg}$ were selected. The animals of the first group (control group, basic variant) were immunized against circovirosis and mycoplasmosis with Ingelvac MycoFLEX ${ }^{\circledR}$ vaccines (series: 27306 2019, ex. 02/05/2019, expiry date 02/05/2021) intramuscularly at a dose of $1.0 \mathrm{ml}+$ Ingelvac CircoFLEX ${ }^{\circledR}$ (series: 30913 16, ex. 02/ $15 / 2019$, expiry date $02 / 15 / 2021$ ) intramuscularly at a dose of $1.0 \mathrm{ml}$, the piglets of the second (experimental group) were injected with biferon-C at a dose of $0.1 \mathrm{ml} / \mathrm{kg}$ simultaneously with vaccines.

The indicated vaccines (manufactured by Boehringer Ingelheim Vetmedica, Inc., USA) and biferon-C (manufactured by Research and Production Center ProBioTech, the Republic of Belarus), containing a mixture of interferons -alpha and -gamma of at least $1 \times 104$ TCD $50 / \mathrm{cm}^{3}$, were used in the experiment.

The blood from the animals $(n=5)$ before the introduction of the drugs (baseline) and in 30 days, was obtained for laboratory studies. The morphological analysis of the blood was performed on an $\mathrm{ABC}$ Micros 60 hematological analyzer. Cellular immunity was studied in accordance with the Methodical Recommendations [32].

Statistical processing of the obtained data was carried out using the Statistica v6.1 program, the reliability was assessed according to the Student's criterion. 


\section{Results and discussion}

During the study period, all experimental piglets were clinically healthy.

Morphological blood tests (Table 1) stated that vaccination and immunization in combination with an immunomodulator were accompanied by a tendency to increase the content of erythrocytes in piglets by 2.5 and $6.2 \%$ and hemoglobin - by 8.2 and $4.3 \%$, respectively.

Table 1. Morphological blood indicators in piglets

\begin{tabular}{|c|c|c|c|}
\hline \multirow{2}{*}{ Indicators } & \multirow{2}{*}{ Baseline } & \multicolumn{2}{|c|}{ After vaccination } \\
\cline { 3 - 4 } & & Control group & $\begin{array}{c}\text { Experimental } \\
\text { group }\end{array}$ \\
\hline Erythrocytes10 $12 / \mathrm{L}$ & $5.16 \pm 0.057$ & $5.29 \pm 0.165$ & $5.48 \pm 0.190$ \\
\hline Hemoglobin g/L & $118.17 \pm 0.936$ & $127.90 \pm 2.240^{\mathrm{xx}}$ & $123.22 \pm 3.543$ \\
\hline Leukocytes, 10\%/L & $13.42 \pm 0.583$ & $13.52 \pm 0.569$ & $13.62 \pm 0.314$ \\
\hline Neutrophils: immature,\% & 0 & 0 & 0 \\
\hline Stab,\% & $2.81 \pm 0.203$ & $4.19 \pm 0.286^{\mathrm{xx}}$ & $3.90 \pm 0.109^{\mathrm{xx}}$ \\
\hline Segmented,\% & $30.67 \pm 1.136$ & $34.60 \pm 1.264^{\mathrm{x}}$ & $33.72 \pm 0.897^{\mathrm{x}}$ \\
\hline Eosinophils,\% & $5.06 \pm 0.285$ & $4.7 \pm 0.28$ & $4.81 \pm 0.174$ \\
\hline Basophils,\% $\%$ & $0.93 \pm 0.018$ & $0.67 \pm 0.057^{\mathrm{xx}}$ & $0.85 \pm 0.044^{*}$ \\
\hline Monocytes, $\%$ & $6.62 \pm 0.151$ & $5.98 \pm 0.251^{\mathrm{x}}$ & $5.98 \pm 0.215^{\mathrm{x}}$ \\
\hline
\end{tabular}

Note. $\times \mathrm{P}<0.05 ; \times \mathrm{P}<0.0001$ relatively to the baseline indicators; $* \mathrm{P}<0.05$; relatively to the indicators of the control group.

The content of leukocytes in animals of the control and experimental groups did not practically differ from the baseline value. The leukogram showed a significant increase in immature forms - stab neutrophils, especially in the baseline variant by $49.1 \%$ (in the experiment - by $38.8 \%$ ), which was associated with an increase in the generation in the bone marrow and subsequent migration of neutrophilic leukocytes into the blood circulation system for phagocytic functions, as well as segmented neutrophils - by 12.8 and $9.9 \%$, respectively.

In piglets of the control and experimental groups, the relative content of eosinophils, which serve as negative modulators of inflammation, decreased by 7.7 and $5.2 \%$, respectively.

The relative number of monocytes, which are precursors of tissue macrophages and perform phagocytic, antigen-presenting and reparative functions, decreased by $10.7 \%$ in animals of both groups.

Biferon-C had a positive effect on cellular nonspecific and adaptive immunity. In piglets of the experimental group, the number of active circulating phagocytes was higher than in the baseline variant by $9.3 \%$, phagocytic index - by $13.0 \%$, phagocytic number - by $23.6 \%$, which indicated the activation of the absorptive function of neutrophils by interferons.

The metabolic (functional) activity of neutrophils in piglets from the experimental group also exceeded that one in animals of the baseline variant. Thus, the spontaneous NBT test, indicating an increase in the cytotoxicity of phagocytes, was by $11.6 \%$ higher in them, and the stimulated NBT test, considered as the criterion of neutrophil readiness for complete phagocytosis, by $17.9 \%$.

At the same time, the functional reserve of cells (PR) was higher than the control indicator by $5.2 \%$, which indicated the activation of the digestive function of phagocytes by interferons (Table 2). 
Table 2. Indicators of the cellular link of nonspecific immunity in piglets

\begin{tabular}{|c|c|c|c|}
\hline \multirow{2}{*}{ Indicators } & \multirow{2}{*}{ Baseline } & \multicolumn{2}{|c|}{ After vaccination } \\
\cline { 3 - 4 } & & Control group & Experimental group \\
\hline PhAL, \% & $59.3 \pm 1.29$ & $50.4 \pm 0.25^{\mathrm{xxx}}$ & $55.1 \pm 0.65^{* \mathrm{x}}$ \\
\hline $\mathrm{PhI}$ & $5.16 \pm 0.342$ & $5.22 \pm 0.060$ & $5.90 \pm 0.029^{* \mathrm{x}}$ \\
\hline PhN & $3.05 \pm 0.203$ & $2.63 \pm 0.027^{\mathrm{x}}$ & $3.25 \pm 0.045^{*}$ \\
\hline spNBT, \% & $40.0 \pm 0.73$ & $46.4 \pm 0.75^{\mathrm{xxx}}$ & $51.8 \pm 0.66^{* \mathrm{xxx}}$ \\
\hline stNBT, \% & $51.7 \pm 0.61$ & $62.4 \pm 0.81^{\mathrm{xxx}}$ & $73.6 \pm 1.03^{\mathrm{xxx}}$ \\
\hline PR & $1.29 \pm 0.024$ & $1.35 \pm 0.026$ & $1.42 \pm 0.034^{\mathrm{xx}}$ \\
\hline
\end{tabular}

Note. $\times \mathrm{P}<0.05 ; \times \mathrm{P}<0.001 ; \times \times \times \mathrm{P}<0.0001$ relatively to the baseline indicators; $* \mathrm{P}<0.0001$ relatively to the indicators of the control group.

Activation of macrophages under the effect of interferons that make up biferon- $\mathrm{C}$, along with an increase in the completion rate of phagocytosis, is associated with an increase in the production of active oxygen metabolites and stimulation of the activity of NO synthase, leading to an increase in the production of nitric oxide, due to which the ability of cells to kill intracellular pathogens significantly increases [33].

Vaccination in combination with biferon-C was accompanied by a less significant (by 6.3 and $5.1 \%$ ) decrease in the relative and absolute content of lymphocytes than in the baseline variant (by $8.0 \%$ ) (Table 3 ).

Table 3. Indicators of cellular immunity in piglets

\begin{tabular}{|c|c|c|c|}
\hline \multirow{2}{*}{ Indicators } & \multirow{2}{*}{ Baseline } & \multicolumn{2}{|c|}{ After vaccination } \\
\cline { 3 - 4 } & & Control group & Experimental group \\
\hline Leukocytes, $10^{9} / \mathrm{L}$ & $13.42 \pm 0.583$ & $13.52 \pm 0.569$ & $13.62 \pm 0.314$ \\
\hline Lymphocytes, $\%$ & $53.9 \pm 1.28$ & $49.9 \pm 1.46^{\mathrm{x}}$ & $50.7 \pm 0.87^{\mathrm{x}}$ \\
abs., $10^{9} / \mathrm{L}$ & $7.26 \pm 0.454$ & $6.72 \pm 0.170$ & $6.91 \pm 0.249$ \\
\hline T-lymphocytes, $\%$ & $48.4 \pm 0.51$ & $41.6 \pm 0.51^{\mathrm{xxx}}$ & $48.0 \pm 0.32^{* * *}$ \\
abs., $10^{9} / \mathrm{L}$ & $3.51 \pm 0.204$ & $2.77 \pm 0.086^{\mathrm{xx}}$ & $3.32 \pm 0.125^{* *}$ \\
\hline T-suppressors, \% & $14.4 \pm 0.60$ & $11.0 \pm 0.32^{\mathrm{xxx}}$ & $10.4 \pm 0.24^{\mathrm{xxx}}$ \\
abs., $10^{9} / \mathrm{L}$ & $0.51 \pm 0.038$ & $0.31 \pm 0.018^{\mathrm{xxx}}$ & $0.35 \pm 0.014^{* \mathrm{xxx}}$ \\
\hline T-helpers., \% & $35.4 \pm 0.81$ & $37.2 \pm 0.37^{\mathrm{x}}$ & $47.2 \pm 0.37^{* * *} \mathrm{xxx}$ \\
abs., $10^{9} / \mathrm{L}$ & $1.24 \pm 0.070$ & $1.03 \pm 0.022^{\mathrm{xx}}$ & $1.57 \pm 0.062^{* * * \mathrm{xx}}$ \\
\hline T-helpers/T- & $2.47: 1 \pm 0.066$ & $3.39: 1 \pm 0.113^{\mathrm{xxx}}$ & $4.54: 1 \pm 0.077^{* * *} \mathrm{xxx}$ \\
suppressors & $15.6 \pm 0.40$ & $19.8 \pm 0.49^{\mathrm{xxx}}$ & $22.4 \pm 0.51^{* * * \mathrm{xxx}}$ \\
\hline B-lymphocytes, \% & $1.13 \pm 0.076$ & $1.33 \pm 0.061^{\mathrm{x}}$ & $1.55 \pm 0.056^{* *} \mathrm{xxx}$ \\
\hline abs., $10^{9} / \mathrm{L}$ & &
\end{tabular}

Note. $\times \mathrm{P}<0.05 ; \times \mathrm{P}<0.001 ; \times \times \times \mathrm{P}<0.0001$ relatively to the baseline indicators; $* \mathrm{P}<0.05$; ** $\mathrm{P}$ $<0.001 ; * * * \mathrm{P}<0.0001$ relatively to the indicators of the control group.

The relative number of T-lymphocytes in piglets of the control group decreased by $16.3 \%$, and in animals of the experimental group it was the same as the baseline value, which indicated the stabilizing effect of biferon-C on T-cell immunity. With a general tendency towards a decrease in the absolute content of T-lymphocytes in animals in the baseline variant, it was more significant (by 26.7\%) than in piglets immunized in combination with an immunomodulator (by 5.7\%).

Quantitative changes also occurred in the T-lymphocyte subpopulations. In piglets vaccinated in combination with biferon-C, the relative and absolute content of theophyllinesensitive T-lymphocytes (suppressors), suppressing the immune response, decreased by 38.5 and $45.7 \%$ and in those immunized without the drug - by 30.9 and $64.5 \%$, respectively. Vaccination of piglets in combination with an immunomodulator stimulated an increase in the formation of T-lymphocytes with helper activity. They had a 33.3 and $26.6 \%$ increase in the relative and absolute number of theophylline-resistant T-cells 
(helpers), which ensured the formation of humoral (antibody synthesis) and cellular immunity and the activation of macrophages.

In the baseline variant, there was a slight $(5.1 \%)$ increase in the relative content of helpers and a decrease in their absolute number by $20.4 \%$.

At the same time, in piglets of the experimental group, a significant increase in the Thelpers/T-suppressors ratio by $83.8 \%$ was recorded, indicating a decrease in the suppressive activity of T-lymphocytes; in the baseline variant, its increase was less significant (by $37.2 \%)$.

The changes in the B-cell link of immunity were characterized by a significant increase in the relative and absolute number of B-lymphocytes, both in the baseline variant by 26.9 and $17.7 \%$, and especially in animals of the experimental group - by 43.6 and $37.2 \%$, respectively.

The positive effect of biferon-C on cellular nonspecific and adaptive immunity in piglets in case of specific prevention of circovirosis and mycoplasmosis is due to the presence of recombinant porcine interferons -alpha and -gamma in its composition. The immunomodulatory effect of interferons lies in their ability to regulate the interaction of cells involved in the immune response [34]. The latter carry out a rapid induction of the endogenous cytokine system. The most pronounced immunomodulatory properties are possessed by endogenous interferon-gamma, which is a key cellular cytokine and an inhibitor of the humoral adaptive immune response, activates Th1 cells, NK cells, macrophages, cytotoxic T lymphocytes, and increases the organism's nonspecific resistance $[34,35]$.

\section{Conclusion}

The conducted studies have detected the immunomodulatory effect of biferon-C on cellular immunity in piglets during the specific prevention of circovirosis and mycoplasmosis, which was manifested by an increase of the absorptive and functional and metabolic activity of phagocytes, the relative and absolute number of T- and B- lymphocytes, T-cells with helper activity and lower formation of the level of T-suppressors, an increase in the Thelpers/T-suppressors ratio in comparison with the baseline variant.

The results obtained indicate that the use of biferon-C is promising for increasing the cellular nonspecific and adaptive immunity in case of specific prevention of circovirosis and mycoplasmosis.

\section{References}

1. B.G. Orlyankin, A.M. Mishin, T.I. Aliper, Act. inf. of pigs' diseases 211-219 (2019)

2. S.A. Raev, Russian. vet. Journal. Agricultural animal breeding, 1, 26-29 (2014)

3. A.V. Kanshina, V.F. Kovalishin, A.S. Yakovleva, M.R. Yakupov, Proceedings of the Fed. center of animal health protection, 13 (1), 96-112 (2015)

4. S.A. Grin, I.N. Matveeva, O.A. Bogomolova, Yu.N. Fedorov, V.M. Popova, E.N. Kryukova, I. Yu. Litenkova, Veterinary Medicine, 12, 20-26 (2019)

5. B.G. Orlyankin, T.I. Aliper, Veterinary Medicine, 1, 3-8 (2020)

6. B. Orlyankin, S. Raev, T. Aliper, Pig breeding, 5, 64-65 (2017)

7. K. Siebel, Pig Progress, 26 (1), 11-13 (2010)

8. B.G. Orlyankin, A.M. Mishin, A.P. Kotelnikov, T.I. Aliper, Veterinary Medicine, 5, 9$11(2014)$ 
9. N.G. Gereev, V.V. Gereeva, E.N. Gogoleva, S.A. Kukushkin, S.N. Chernyshov, S.A. Evtushok, Pig breeding, 5, 61-62 (2019)

10. M.V. Biryuchenkova, A.M. Timina, A.V. Shcherbakov, Proceedings of the Fed. center of animal health protection, 16, 265-281 (2018)

11. H. Bak, E. Nörregård, Proceedings of the 21st IPVS Congress, Vancouver, Canada July 18-21. 140 (2010)

12. M. Misener, Proceedings of the 21st IPVS Congress, Vancouver, Canada - July 18-21. $342(2010)$

13. J. Nerem, Proceedings of the 21st IPVS Congress, Vancouver, Canada - July 18-21. 170 (2010)

14. A.F. Ovcherenko, S.P. Demin, D.N. Pilyugin, N.A. Isakova, M.V. Sorokin, D. Gebrauskas, A. Shmatavichus, I. Sabo, P.M. Sabo, Veterinary Medicine, 10, 33 - 37 (2008)

15. E. Fano, C. Pijoan, S. Dee, Can. J. Vet. Res, 69 (3), 223-228 (2005)

16. M. Bandrick, M. Pieters, C. Pijoan, T.W. Molitor, Clin. Vaccine Immunol, 15 (3), 540543 (2008)

17. M. Young, G. Cunningham, E. Sanford, Pig Production, 1, 60-62 (2011)

18. A.B. Chalchenko, S.A. Kukushkin, Yu.I. Eremin, B.V. Abramyan, Pig breeding, 6, 4041 (2012)

19. D. Lopart, D. Kasal, D. Clota et al., Sp. vet. Med, 1(6), 5-9 (2006)

20. Beilage E Grousse, A. Schreiber, Dtsch Tierarztl Wochenschr. 112 (7), 256-261 (2005)

21. V.P. Khlopitskiy, Yu.N. Brigadirov, V.N. Kotsarev, T.I. Ermakova, P.A. Parshin, G.A. Vostroilova, Veterinary Medicine, 8, 15-20 (2018)

22. A.V. Andreeva, O. N. Nikolaeva, Bulletin of Bashkir. state agr. un. 2(30), 42-44 (2014)

23. A.G. Shakhov, M.I. Retskiy, Yu.N. Masyanov, Yu.N. Brigadirov, A.M. Zayko, Act. problems of inf. pat. and immun. of animals, 667-668 (2006)

24. A.V. Deeva, G.G. Mekhdikhanov, V.D. Sokolov, R.V. Belousova, Veterinary medicine, 6, 8-12 (2008)

25. E.V. Krapivina, D.V. Ivanov, A.I. Feskov, A.I. Albulov, M.A. Frolova, O.V. Bukhantsev, Vet. med. and feeds. 1, 30-32 (2012)

26. V.A. Prokulevich, M.I. Potapovich, Bulletin of BSU, 3, 51-54 (2011)

27. L. Krakowski et all. Vet. Imm. and Immunopath. 87, 84-95 (2002)

28. F.P. Petryankin, O. Yu. Petrova, Vet. pat. 1, 70-73 (2008)

29. F. Blecha, Vet. Clin. of N. Am.: Food An. Pract.17, 621-633 (2001)

30. K.V. Kudin, I.V. Kudina, V.A. Prokulevich, Biotech: achievements and perspectives of development. Collection. of mat. of the III int. scientific and practical conf. 78-81 (2018)

31. V.V. Zaytsev, M.O. Biletskiy, O.R. Biletskiy, A.V. Zaytseva, Scientific notes of the EI VSAVM, 54 (1), 9-13 (2018)

32. A.G. Shakhov, Yu.N. Brigadirov, A.I. Anufriev et al., Guidelines for the assessment and correction of animal resistance (Voronezh, 2005)

33. S.A. Ketlinskiy, A.S. Simbirtsev, Cytokines (St. Petersburg, Foliant, 2008)

34. T.V. Sologub, V.V. Tsvetkov, E.G. Deeva, Russian. med. and biol. bulletin named after acad. I.P. Pavlov, 22 (3), 56-60 (2014) 
35. A. N. Moiseev, P.I. Baryshnikov, Veterinary Medicine, 3, 50-54 (2016) 